Article

\title{
Evaluating the Effectiveness of Essential Oils and Combination of Copper and Lactic Acid on the Growth of E. coli O157:H7 in Laboratory Medium
}

\author{
Tarik Bor, Rabin Gyawali and Salam A. Ibrahim *
}

Food Microbiology and Biotechnology Laboratory, North Carolina Agricultural and Technical State University, Greensboro, NC 27411, USA; tarikbor@gmail.com (T.B.); rgyawali@aggies.ncat.edu (R.G.)

* Correspondence: ibrah001@ncat.edu; Tel.: +1-336-285-4860; Fax: +1-336-334-7239

Academic Editor: Esther Sendra

Received: 6 December 2015; Accepted: 17 February 2016; Published: 23 February 2016

\begin{abstract}
In this study, we compared the effectiveness of armoise and clove bud essential oils (EOs) and the combination of low concentrations of copper $(\mathrm{Cu})$ and lactic acid (LA) against E. coli O157:H7 in a laboratory medium. Three strains of Escherichia coli O157:H7 (ATCC700599, ATCC51659, and ATCC43895) were used in this study. Antibacterial activity was determined by measuring the turbidity of a broth medium and by determination of bacterial populations. Our results showed that armoise $(0.15 \% v / v)$, clove bud $(0.1 \% v / v)$ EOs, or Cu $(50 \mathrm{ppm})$ in combination with LA $(0.2 \% v / v)$ caused a minimum $5.0 \log$ reduction of E. coli O157:H7 in the laboratory medium. $\mathrm{Cu}$ in combination with LA may thus be preferable to EOs in food in order to control the growth of foodborne pathogens. In addition, the combination treatment of $\mathrm{Cu}$ and LA could provide the food industry with a practical approach to reducing the risk of foodborne pathogens.
\end{abstract}

Keywords: E. coli O157:H7; copper; lactic acid; armoise; clove bud; essential oil

\section{Introduction}

Despite advances in food safety, each year roughly 48 million people get sick, 128,000 people are hospitalized and 3000 people die because of foodborne diseases [1]. Due to recent outbreaks of illnesses caused by foodborne pathogens, consumers have been paying more attention to food safety. E. coli O157:H7 is one of the major foodborne pathogens that can cause severe illness such as diarrhea and acute kidney failure [1]. Different preservation methods such as pasteurization, irradiation, vacuum packaging and chemical preservatives have been used to control foodborne pathogens [2]. Consumers are not only paying more attention to foodborne pathogens but are also concerned with the use of chemical preservatives to control pathogens in food products [3]. Consumers are demanding minimally processed, safe, shelf-stable foods and prefer natural ingredients [4].

Recently, our laboratory studied the effects of the combination of copper $(\mathrm{Cu})$ and lactic acid (LA) on the growth of E. coli O157:H7 and discovered that low concentrations of both Cu and LA could inhibit the growth of foodborne pathogens including E. coli O157:H7 and Salmonella spp. [5,6]. This approach appears to be very practical for the food industry in order to reduce the risk of foodborne pathogens. Moreover, the combination treatment of $\mathrm{Cu}$ and LA is water-soluble and can be a low-cost treatment method compared to treatment with other natural ingredients.

Essential oils (EOs) are common natural preservatives that have been effectively tested against foodborne pathogens. However, the insolubility of EOs in water and their strong aroma could negatively impact the sensory perception of consumers and thus limit the use of EOs in food products [7]. Previous studies in our laboratory showed that low concentrations of Cu and LA 
could achieve a $5 \log$ reduction of E. coli O157:H7 [5,6]. However, there is a need to conduct a study to validate the effectiveness of low concentrations of copper and lactic acid as antimicrobials with other known natural ingredients such as EOs. Therefore, the objective of this study was to evaluate the effectiveness of EOs (armoise and clove oils) and the combination of $\mathrm{Cu}$ and LA to control the growth of E. coli $\mathrm{O} 157: \mathrm{H7}$ in a laboratory medium.

\section{Experimental Section}

\subsection{Bacterial Strains and Inoculm Prpearation}

Three strains of E. coli O157:H7, ATCC 700599 (salami isolate), ATCC 51659 (clinical isolate), and ATCC 43895 (raw hamburger meat isolate), were individually grown in BHI (Difco, Becton Dickinson, Sparks, MD, USA) at $37^{\circ} \mathrm{C}$ for $24 \mathrm{~h}$. Overnight cultures of the strains were centrifuged $(8000 \mathrm{~g}, 15 \mathrm{~min}$ at $4{ }^{\circ} \mathrm{C}$ ), supernatant of each strain was decanted and the cell pellet was re-suspended (approximately $8.0 \log \mathrm{CFU} / \mathrm{mL})$ in $0.1 \%(\mathrm{v} / \mathrm{v}) 10 \mathrm{ml}$ peptone water. Individual strains were prepared by mixing $1 \mathrm{~mL}$ of each overnight strain in $9.0 \mathrm{~mL}$ of peptone water. Several decimal dilutions were then made to achieve an initial inoculum level of $2-3 \log \mathrm{CFU} / \mathrm{mL}$.

\subsection{Experimental Design}

Armoise (Artemisia alba, armoise EO, Batch No. 1444, Origin: Morocco, Aromatics Inc., Ontario, Canada) and clove bud (Syzygium aromaticum, Organic clove bud oil, Origin: Madagascar, Simplers Botanicals) EOs were purchased from local stores in Greensboro, NC, and kept at $4{ }^{\circ} \mathrm{C}$ for $24 \mathrm{~h}$. EOs were mixed with sterilized Tween 80 (1:1) (Fisher Scientific, Pittsburgh, PA, USA) and added into sterilized BHI broth to obtain $0.006 \%, 0.0125 \%, 0.025 \%, 0.05 \%, 0.1 \%, 0.15 \%, 0.2 \%$, and $0.25 \%(v / v)$ concentrations. Seven $\mathrm{mL}$ batches of samples from each portion were dispensed into sterile test tubes. Seven $\mathrm{mL}$ of BHI broth without EOs were used as control samples. Along with the treatment samples, a blank sample containing the same treatment concentrations were used to correct the sample readings. Each set of experimental tests was conducted in triplicates.

The antimicrobial activity of low-concentration $\mathrm{Cu}$ and LA was tested according to the method described by Gyawali et al. [5]. In this procedure, $7.0 \mathrm{~mL}$ batches of fresh $\mathrm{BHI}$ broth containing copper sulfate pentahydrate $\left(\mathrm{CuSO}_{4} \cdot 5 \mathrm{H}_{2} \mathrm{O}\right.$, Thermo Fisher Scientific, Fair Lawn, NJ, USA) at concentrations of 25 and $50 \mathrm{ppm}(w / v)$, LA at $0.1 \%, 0.15 \%$ and $0.2 \%(v / v)(85 \%$, Thermo Fisher Scientific, Fair Lawn, NJ, USA) and their combinations were prepared. An additional $7.0 \mathrm{~mL}$ of BHI broth that was not supplemented with any chemical was used as a control. Samples containing the control and LA were autoclaved at $121^{\circ} \mathrm{C}$ for $15 \mathrm{~min}$. The $\mathrm{Cu}$ solution was filter sterilized through a $0.2 \mu \mathrm{m}$ Nalgene filtration product (Nalge Nunc International, Rochester, NY, USA) and added to the BHI broth at varying concentrations.

\subsection{Measuring Bacterial Growth}

Bacterial growth was monitored by measuring turbidity at two-hour time intervals during incubation at $37^{\circ} \mathrm{C}$ over $8 \mathrm{~h}$ using a GENESYS ${ }^{\mathrm{TM}} 10 \mathrm{~S}$ UV-Vis spectrophotometer (Thermo Electron Scientific Co., Madison, WI, USA) at a $610 \mathrm{~nm}$ wavelength.

\subsection{Bacterial Enumeration}

Bacterial populations were determined by plating onto BHI agar. In this procedure, samples $(1 \mathrm{~mL})$ were withdrawn from inoculated samples at the beginning $(0 \mathrm{~h})$ and end $(8 \mathrm{~h})$ of the incubation period and serially diluted in $0.1 \%$ peptone water. Then, appropriate dilutions were surface-plated $(100 \mu \mathrm{L})$ onto duplicate BHI agar and colonies were counted after plates were incubated at $37^{\circ} \mathrm{C}$ for $24 \mathrm{~h}$. 


\subsection{Statistical Analysis}

Different treatments were statistically analyzed for their antimicrobial effects on E. coli O157:H7 by factorial analysis of variance of duplicate samples. Each experiment was conducted in replicates to determine the effects of $\mathrm{Cu}$ and LA combination treatment, armoise EO and clove bud EO on the survival and growth of the bacterial strains. Data from the three experiments were pooled to calculate the statistical mean and standard error of the mean for each treatment. Data were verified for normality, followed by an analysis of variance $(p<0.05)$ using SAS version 9.2 (SAS Institute, Cary, NC, USA).

\section{Results and Discussion}

\subsection{Antibacterial Activity of Armoise and Clove Bud EOs against E. coli O157:H7 in BHI Medium}

Figures 1-6 show survival and growth of three strains of E. coli O157:H7 (ATCC700599, ATCC51659, and ATCC43895) in BHI medium with different concentrations of armoise and clove bud EOs during incubation at $37^{\circ} \mathrm{C}$ for $8 \mathrm{~h}$. In the control samples, the initial growth as determined by turbidity at $610 \mathrm{~nm}$ was $\sim 0.0$. The bacterial strains continued to grow during the incubation period and reached the stationary phase within $6-8 \mathrm{~h}$. Turbidity readings reached $\sim 0.80$ after $8 \mathrm{~h}$. With the addition of armoise $\mathrm{EO}$ at low concentrations $(0.025 \%$ and $0.05 \%)$, turbidity readings were similar to the control samples, while high concentrations of armoise EO $(\geqslant 0.1 \%)$ inhibited the growth of all tested strains as evidenced by low turbidity readings. Turbidity readings were $\sim 0.50$ with the addition of clove bud EO at low concentrations $(0.006 \%)$, and $\sim 0.0$ at high concentrations $(\geqslant 0.0125)$.

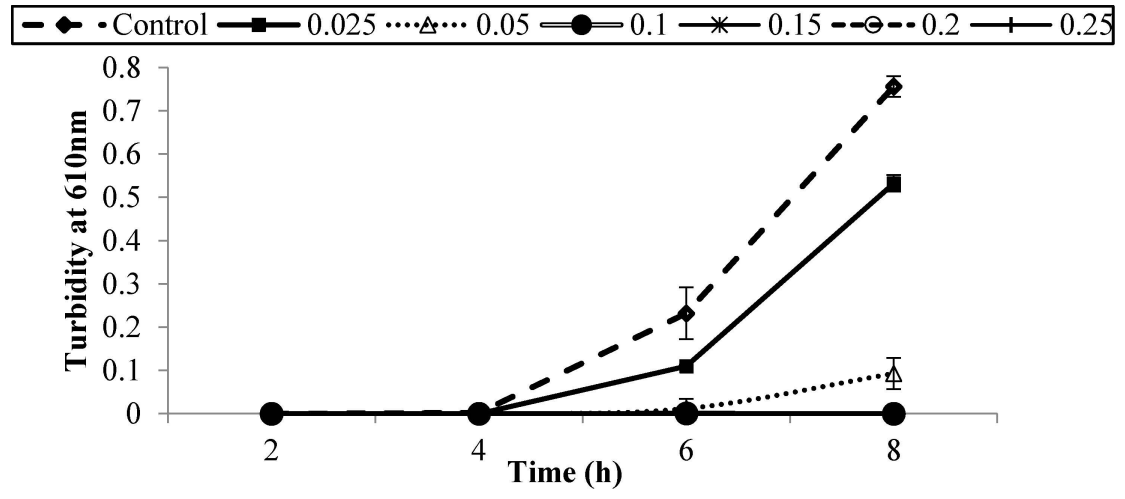

Figure 1. Survival and growth of E. coli O157:H7 (ATCC 700599) in BHI medium with different concentrations of armoise EO $(\%, v / v)$ after $8 \mathrm{~h}$ incubation at $37^{\circ} \mathrm{C}$. Symbols represent means of triplicate replications $(n=3)$; error bars depict standard deviation from the sample mean.

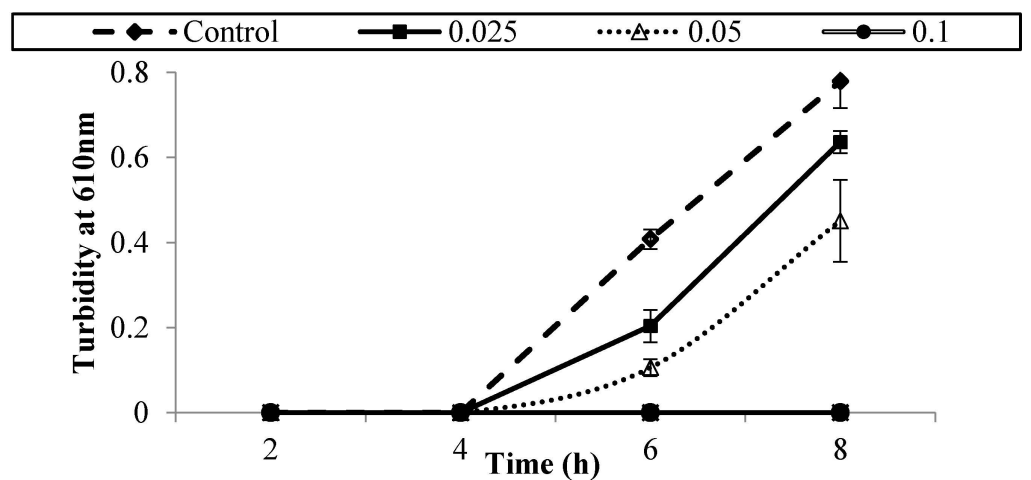

Figure 2. Survival and growth of E. coli O157:H7 (ATCC 51659) in BHI medium with different concentrations of armoise EO $(\%, v / v)$ after $8 \mathrm{~h}$ incubation at $37^{\circ} \mathrm{C}$. Symbols represent means of triplicate replications $(n=3)$; error bars depict standard deviation from the sample mean. 


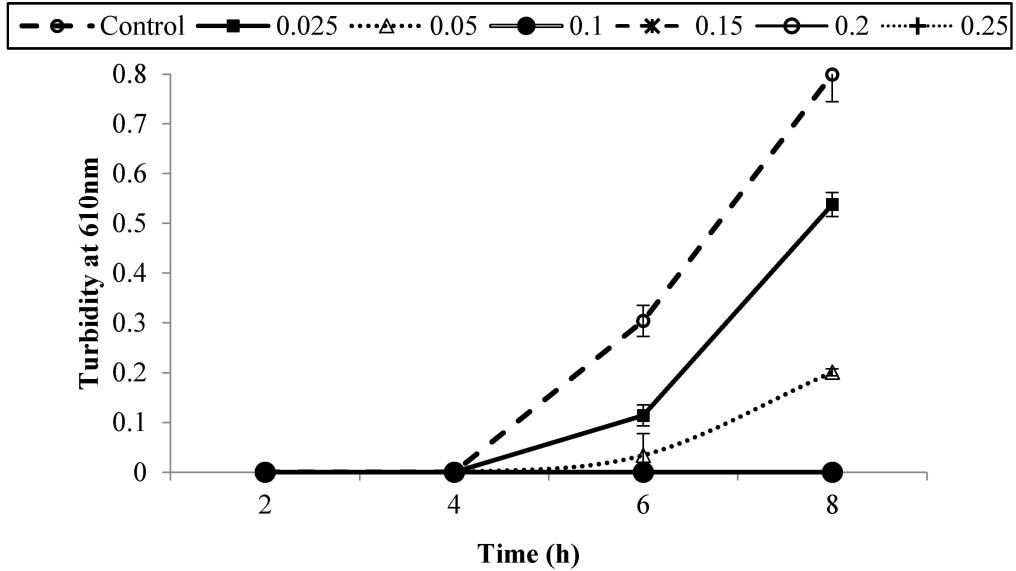

Figure 3. Survival and growth of E. coli O157:H7 (ATCC 43895) in BHI medium with different concentrations of armoise EO $(\%, v / v)$ after $8 \mathrm{~h}$ incubation at $37^{\circ} \mathrm{C}$. Symbols represent means of triplicate replications $(n=3)$; error bars depict standard deviation from the sample mean.

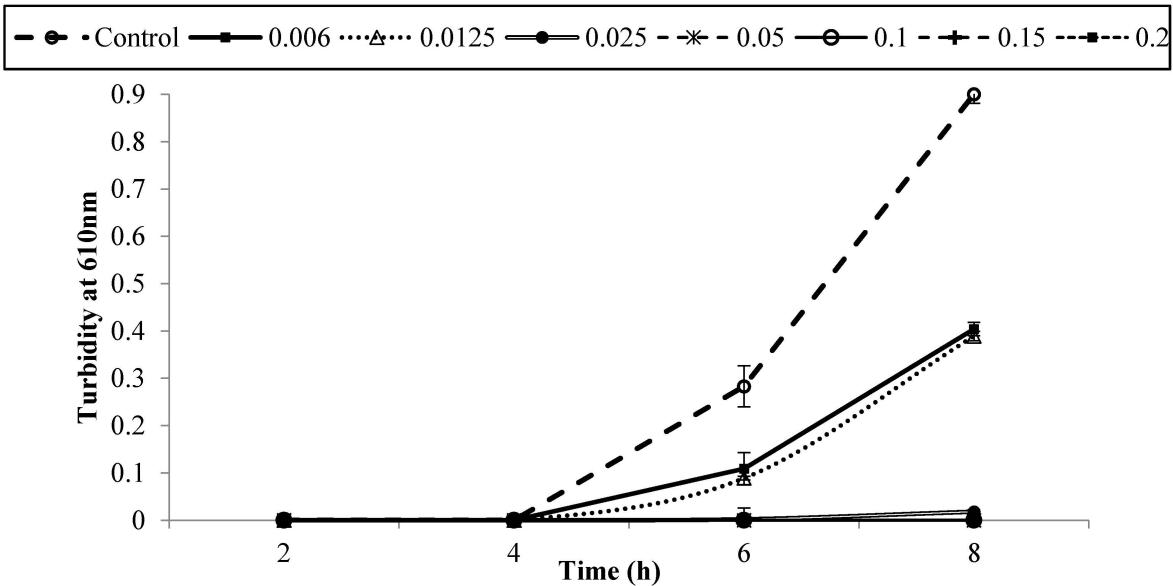

Figure 4. Survival and growth of E. coli O157:H7 (ATCC 700599) in BHI medium with different concentrations of clove bud EO $(\%, v / v)$ during incubation at $37^{\circ} \mathrm{C}$ for $8 \mathrm{~h}$. Symbols represent means of triplicate replications $(n=3)$; error bars depict standard deviation from the sample mean.

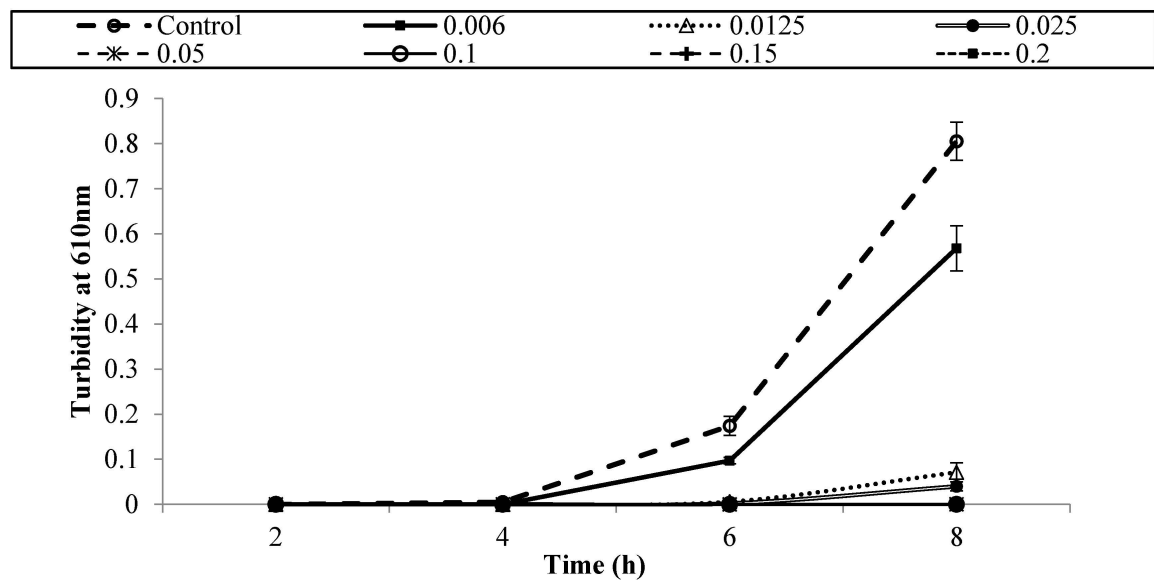

Figure 5. Survival and growth of E. coli O157:H7 (ATCC 51659) in BHI medium with different concentrations of clove bud EO $(\%, v / v)$ during incubation at $37{ }^{\circ} \mathrm{C}$ for $8 \mathrm{~h}$. Symbols represent means of triplicate replications $(n=3)$; error bars depict standard deviation from the sample mean. 


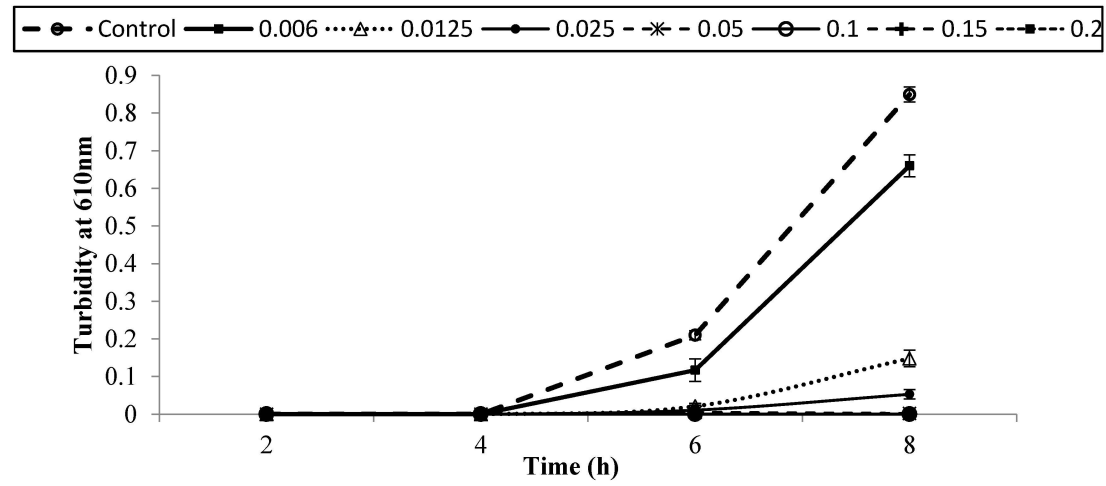

Figure 6. Survival and growth of E. coli O157:H7 (ATCC 43895) in BHI medium with different concentrations of clove bud EO $(\%, v / v)$ during incubation at $37{ }^{\circ} \mathrm{C}$ for $8 \mathrm{~h}$. Symbols represent means of triplicate replications $(n=3)$; error bars depict standard deviation from the sample mean.

At the end of the incubation period, the population of all tested strains was determined (Tables 1 and 2). In control samples, the population of E. coli O157:H7 increased from $~ 2-3 \log \mathrm{CFU} / \mathrm{mL}$ of initial population to $\sim 8.8 \log \mathrm{CFU} / \mathrm{mL}$ after $8 \mathrm{~h}$. With the addition of armoise and clove bud EOs at low concentrations $(\leqslant 0.0125 \%)$, growth was similar to the control samples; however, at high $(\geqslant 0.15 \%)$ concentrations the population of all tested strains was $<1 \log \mathrm{CFU} / \mathrm{mL}$. Based on turbidity readings and populations of tested strains, our results indicated that the armoise and clove bud EOs at $0.1 \%(v / v)$ inhibited the growth of all tested strains in BHI broth medium. These results are supported by Imelouane et al. [8], who showed that Artemisia herba-Alba Asso. EO at a $0.66 \mathrm{mg} / \mathrm{mL}$ concentration inhibited the growth of E. coli O157:H7 in TSB. Similarly, Friedman et al. [9] found that clove bud EO exerted bactericidal activity against E. coli O157:H7 when tested in an aqueous phosphate-saline buffer ( $\mathrm{pH}$ 7.0).

Table 1. Population of E. coli O157:H7 in Brain Heart Infusion (BHI) broth medium in the presence of armoise essential oil (EO) at different concentrations after incubation at $37^{\circ} \mathrm{C}$ for $8 \mathrm{~h}$.

\begin{tabular}{cccc}
\hline \multirow{2}{*}{ Treatment $(\%$ v/v) } & \multicolumn{3}{c}{ Population of E. coli O157:H7 Strains $(\log$ CFU/mL) } \\
\cline { 2 - 4 } & ATCC 700599 & ATCC 51659 & ATCC 43895 \\
\hline Control & $9.01 \pm 0.11^{\mathrm{a}}$ & $8.82 \pm 0.11^{\mathrm{a}}$ & $8.41 \pm 0.53^{\mathrm{a}}$ \\
EO 0.025 & $8.26 \pm 0^{\mathrm{b}}$ & $8.68 \pm 0.26^{\mathrm{a}}$ & $8.22 \pm 0.29^{\mathrm{b}}$ \\
EO 0.05 & $8.1 \pm .005^{\mathrm{b}}$ & $7.96 \pm 0.18^{\mathrm{b}}$ & $6.93 \pm 0.28^{\mathrm{c}}$ \\
EO 0.1 & $<1^{\mathrm{c}}$ & $2.34 \pm 0.19^{\mathrm{c}}$ & $<1^{\mathrm{d}}$ \\
EO 0.15 & $<1^{\mathrm{c}}$ & $<1^{\mathrm{d}}$ & $<1^{\mathrm{d}}$ \\
EO 0.2 & $<1^{\mathrm{c}}$ & $<1^{\mathrm{d}}$ & $<1^{\mathrm{d}}$ \\
EO 0.25 & $<1^{\mathrm{c}}$ & $<1^{\mathrm{d}}$ & $<1^{\mathrm{d}}$ \\
\hline
\end{tabular}

Initial inoculum level was 2-3 log CFU/mL. Statistically different treatments $(p<0.05)$ within same column are shown with different letters. Values $(\log \mathrm{CFU} / \mathrm{mL})$ are mean \pm standard deviation $(n=3)$.

Table 2. Population of E. coli O157:H7 with the presence of clove bud essential oil (EO) at different concentrations (\% v/v) in Brain Heart Infusion (BHI) broth medium after incubation at $37^{\circ} \mathrm{C}$ for $8 \mathrm{~h}$.

\begin{tabular}{cccc}
\hline \multirow{2}{*}{ Treatment $(\%$ v/v) } & \multicolumn{3}{c}{ Population of E. coli O157:H7 Strains $(\log$ CFU/mL) } \\
\cline { 2 - 4 } & ATCC 700599 & ATCC 51659 & ATCC 43895 \\
\hline Control & $8.48 \pm 0.05^{\mathrm{a}}$ & $8.52 \pm 0.47^{\mathrm{a}}$ & $7.23 \pm 0.26^{\mathrm{a}}$ \\
EO 0.006 & $7.71 \pm 0.04^{\mathrm{b}}$ & $7.22 \pm 0.35^{\mathrm{b}}$ & $6.74 \pm 0.13^{\mathrm{a}}$ \\
EO 0.0125 & $7.06 \pm 0.02^{\mathrm{c}}$ & $5.2 \pm 0.14^{\mathrm{c}}$ & $4.66 \pm 0.19^{\mathrm{b}}$ \\
EO 0.025 & $3.06 \pm 0.41^{\mathrm{d}}$ & $4.6 \pm 0.11^{\mathrm{d}}$ & $4.23 \pm 0.59^{\mathrm{b}}$ \\
EO 0.05 & $2.27 \pm 0.04^{\mathrm{e}}$ & $1.94 \pm 0.02^{\mathrm{e}}$ & $1.89 \pm 0.01^{\mathrm{c}}$ \\
EO 0.1 & $<1^{\mathrm{f}}$ & $<1^{\mathrm{f}}$ & $<1^{\mathrm{d}}$ \\
EO 0.15 & $<1^{\mathrm{f}}$ & $<1^{\mathrm{f}}$ & $<1^{\mathrm{d}}$ \\
EO 0.2 & $<1^{\mathrm{f}}$ & $<1^{\mathrm{f}}$ & $<1^{\mathrm{d}}$ \\
\hline
\end{tabular}

Initial inoculum level was $2-3 \log \mathrm{CFU} / \mathrm{mL}$. Statistically different treatments $(p<0.05)$ within same column are shown with different letters. Values $(\log \mathrm{CFU} / \mathrm{mL})$ are mean \pm standard deviation $(n=3)$. 


\subsection{Antibacterial Activity of Copper (Cu) and Lactic Acid (LA) against E. coli O157:H7 in BHI Medium}

Figures 7-9 show survival and growth of E. coli O157:H7 strains (ATCC 700599, ATCC 51659 and ATCC 43895) in the presence of $\mathrm{Cu}$ and LA at different concentrations during incubation at $37^{\circ} \mathrm{C}$ for $8 \mathrm{~h}$. The bacterial strains continued to grow during the incubation period and reached the stationary phase within $6-8 \mathrm{~h}$. The turbidity readings reached an absorbance of $\sim 0.82$. When $\mathrm{Cu}$ was added to $\mathrm{BHI}$ broth at a concentration of $25 \mathrm{ppm}$, absorbance was $\sim 0.34$, and at a concentration of $50 \mathrm{ppm} \mathrm{Cu}$, absorbance was $\sim 0.21$. The growth of bacterial strains was similar to the control with the addition of LA at concentrations of $0.1 \%$ and $0.15 \%$. However, when a combination of $\mathrm{Cu}$ ( 25 and $50 \mathrm{ppm}$ ) and LA $(0.1 \%$ and $0.15 \%)$ was used, the turbidity reading was 0.0 .

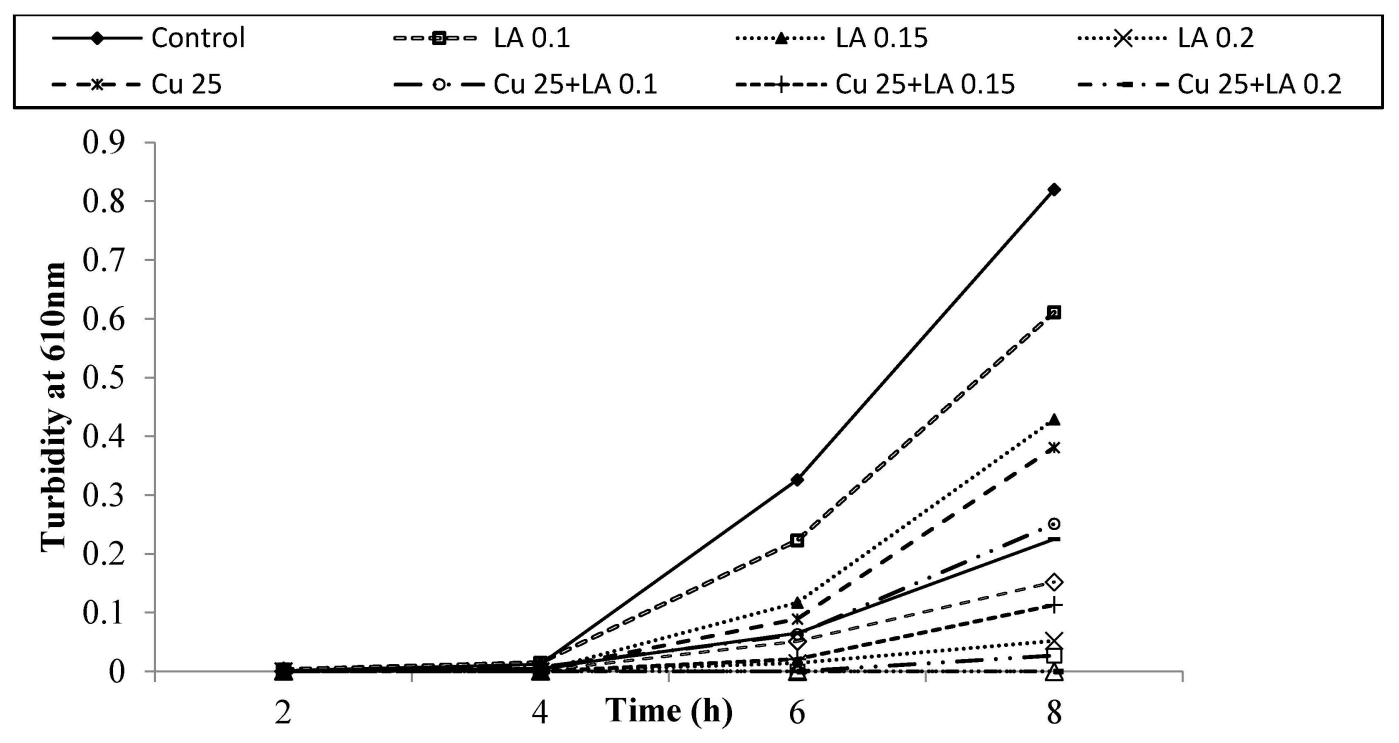

Figure 7. Survival and growth of E. coli ATCC 700599 in BHI broth with copper (ppm, w/v) and lactic acid $(\% v / v)$ at different concentrations during incubation at $37^{\circ} \mathrm{C}$ for $8 \mathrm{~h}$.

\begin{tabular}{|c|c|c|c|}
\hline$\longrightarrow$ Control & $=0$ LA 0.1 & $\cdots \cdots . \cdots \cdots \cdot$ LA 0.15 & …........ LA 0.2 \\
\hline$--*--C u 25$ & - o. - Cu 25+LA 0.1 & $---+--\cdot$ Cu 25+LA 0.15 & $-\cdots-\operatorname{Cu} 25+$ LA 0.2 \\
\hline$-\mathrm{Cu} 50$ & $--\diamond--$ Cu 50+LA 0.1 & 一 & $\cdots \cdot A \cdots$. \\
\hline
\end{tabular}

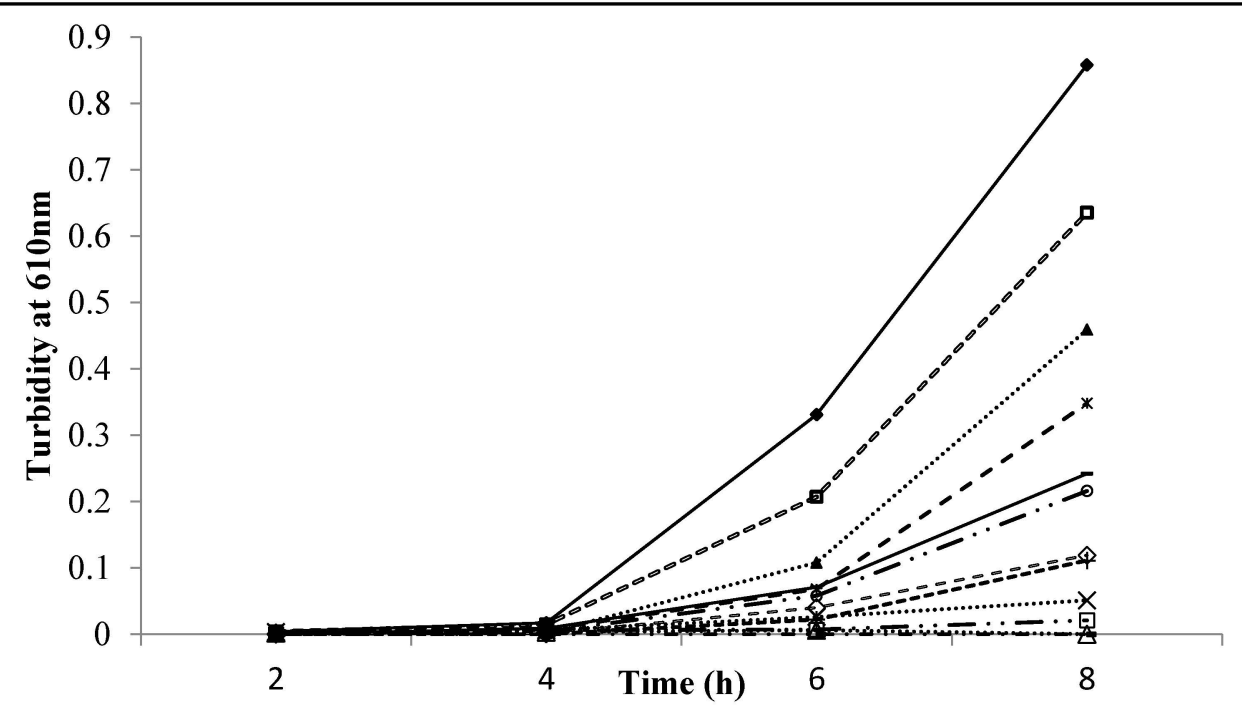

Figure 8. Survival and growth of E. coli ATCC 51659 in BHI broth with copper (ppm, w/v) and lactic $\operatorname{acid}(\% v / v)$ at different concentrations during incubation at $37^{\circ} \mathrm{C}$ for $8 \mathrm{~h}$. 


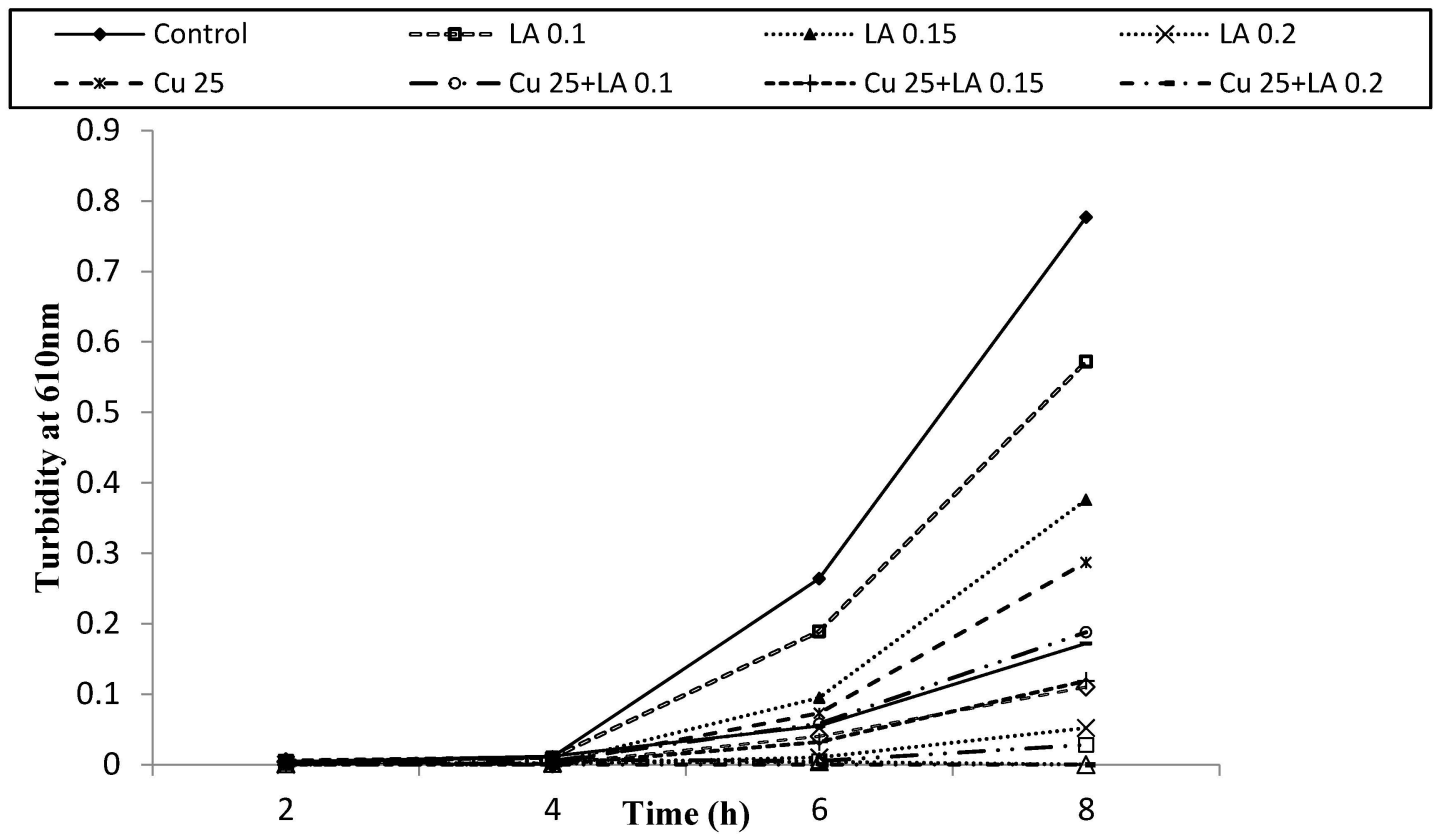

Figure 9. Survival and growth of E. coli ATCC 43895 in BHI broth with copper (ppm, w/v) and lactic acid $(\% v / v)$ at different concentrations during incubation at $37^{\circ} \mathrm{C}$ for $8 \mathrm{~h}$.

Table 3 shows the population of E. coli O157:H7 in the presence of different concentrations of $\mathrm{Cu}$ and LA after incubation at $37^{\circ} \mathrm{C}$ for $8 \mathrm{~h}$. In the control samples, the population of E. coli O157:H7 increased from $\sim 2.0$ to $3.0 \log \mathrm{CFU} / \mathrm{mL}$ to $\sim 9.0 \log \mathrm{CFU} / \mathrm{mL}$ after $8 \mathrm{~h}$. Cu or LA alone slightly inhibited the growth of tested strains ( 2.0 log reduction). The combination of $\mathrm{Cu}(25$ and $50 \mathrm{ppm})$ with LA $(0.1 \%$ and $0.15 \%$ ) caused a $\sim 4.0 \log$ reduction, while Cu $50 \mathrm{ppm}$ and LA $0.2 \%$ caused a $\sim 7.0 \log$ reduction on the growth of E. coli O157:H7. Our results indicated that $\mathrm{Cu}$ and LA alone had a slight effect on the growth of E. coli O157:H7 in the laboratory medium. The combination of $\mathrm{Cu}$ and LA showed significant growth inhibition for all tested strains $(p<0.05)$. Al-Holy et al. [10] investigated the effect of LA, $\mathrm{Cu}$ (II), and monolaurin as natural antimicrobials against Cronobacter in infant formula. These authors showed that a complete elimination of Cronobacter was obtained when a combination of sub-lethal concentrations of LA $(0.2 \%)$ and $\mathrm{Cu}$ (II) (50 ppm) was used. The results indicate that $\mathrm{Cu}$ and LA could be used to control the growth of a wide range of pathogens.

The Food and Drug Administration (FDA) requires food processors to achieve at least a 5.0 log reduction of pathogens in their finished products [11]. This ruling has prompted the search for other novel non-thermal preservation methods that can ensure product safety. In our study, we have demonstrated the combination treatment of $\mathrm{Cu}$ and LA as a potentially promising non-thermal food preservation method which meets the US FDA's requirement of a mandatory 5.0 log reduction. The synergistic effect of $\mathrm{Cu}$ and LA in carrot juice samples was shown in our previous studies [6]. In our current study, we demonstrated that armoise and clove bud oils at certain concentrations reduced the number of tested strains by at least $5 \mathrm{log}$ in laboratory medium. We also showed that $\mathrm{Cu}$ and LA at low concentrations caused at least a $5 \log$ reduction of tested strains. In recent years, there has been an increased interest in the use of natural antimicrobial agents, especially Eos, to control foodborne bacteria and other pathogenic microorganisms. EOs have antibacterial and antioxidant properties and can be used in different applications to ensure food safety [12]. However, EOs are expensive and are not water-soluble. To achieve a $5.0 \mathrm{log}$ reduction, EOs need to be added above the solubility limit, and that could have an impact on the flavor and appearance of the food and affect overall sensory properties. $\mathrm{Cu}$ at a low concentration is relatively safe and non-toxic for humans and is considered an essential micronutrient and cofactor for certain enzymes [6]. 
Table 3. Population of E. coli O157:H7 in BHI medium in the presence of lactic acid (LA) at $0.1 \%, 0.15 \%$, and $0.2 \% v / v$ and copper $(\mathrm{Cu})$ at 25 and $50 \mathrm{ppm}$ concentrations after incubation at $37^{\circ} \mathrm{C}$ for $8 \mathrm{~h}$.

\begin{tabular}{cccc}
\hline \multirow{2}{*}{ Treatment } & \multicolumn{2}{c}{ Population of E. coli O157:H7 Strains (log CFU/mL) } \\
\cline { 2 - 4 } & ATCC 700599 & ATCC 51659 & ATCC 43895 \\
\hline CONTROL & $8.79 \pm 0.21^{\mathrm{a}}$ & $8.70 \pm 0.25^{\mathrm{a}}$ & $8.74 \pm 0.23^{\mathrm{a}}$ \\
LA 0.1 & $8.55 \pm 0.23^{\mathrm{a}}$ & $8.18 \pm 0.56^{\mathrm{ab}}$ & $8.35 \pm 0.19^{\mathrm{ab}}$ \\
LA 0.15 & $8.1 \pm 0.30^{\mathrm{ab}}$ & $7.46 \pm 0.27^{\mathrm{bc}}$ & $6.55 \pm 0.16^{\mathrm{d}}$ \\
LA 0.2 & $5.69 \pm 0.08^{\mathrm{e}}$ & $5.49 \pm 0.38^{\text {ef }}$ & $6.10 \pm 0.41^{\mathrm{de}}$ \\
Cu 25 ppm & $7.62 \pm 0.14^{\mathrm{bc}}$ & $6.98 \pm 0.63^{\mathrm{cd}}$ & $7.77 \pm 0.32^{\mathrm{bc}}$ \\
Cu 25 + LA 0.1 & $6.98 \pm 0.18^{\mathrm{c}}$ & $6.40 \pm 0.20^{\mathrm{cde}}$ & $7.28 \pm 0.41^{\mathrm{c}}$ \\
Cu 25 + LA 0.15 & $6.01 \pm 0.48^{\mathrm{de}}$ & $6.18 \pm 0.27^{\mathrm{de}}$ & $5.46 \pm 0.23^{\text {ef }}$ \\
Cu 25 + LA 0.2 & $4.58 \pm 0.26^{\mathrm{f}}$ & $4.92 \pm 0.21^{\mathrm{f}}$ & $4.58 \pm 0.26^{\mathrm{g}}$ \\
Cu 50 & $7.16 \pm 0.61^{\mathrm{c}}$ & $6.98 \pm 0.81^{\mathrm{bd}}$ & $6.47 \pm 0.15^{\mathrm{d}}$ \\
Cu 50 + LA 0.1 & $6.79 \pm 0.40^{\mathrm{cd}}$ & $5.31 \pm 1.19^{\text {ef }}$ & $5.01 \pm 0.47^{\mathrm{fg}}$ \\
Cu 50 + LA 0.15 & $5.28 \pm 0.49^{\text {ef }}$ & $4.80 \pm 0.10^{\mathrm{f}}$ & $3.24 \pm 0.15^{\mathrm{h}}$ \\
Cu 50 + LA 0.2 & $1.61 \pm 0.67^{\mathrm{g}}$ & $1.50 \pm 0.92^{\mathrm{g}}$ & $0.84 \pm 0.20^{\mathrm{i}}$ \\
\hline
\end{tabular}

Initial inoculum level was 2-3 $\log \mathrm{CFU} / \mathrm{mL}$. Statistically different treatments $(p<0.05)$ within same column are shown with different letters. Values $(\log \mathrm{CFU} / \mathrm{mL})$ are mean \pm standard deviation $(n=3)$.

Due to its strong antimicrobial effect at low concentrations, low cost of chemicals, lack of negative impact on sensory properties, lack of binding with lipids and protein components, and due to its water solubility properties, $\mathrm{Cu}$ in combination with LA would be superior to EOs at inhibiting the growth of microorganisms to ensure the safety of food products.

\section{Conclusions}

Our study revealed that armoise $(0.15 \% v / v)$ and clove bud $(0.1 \% v / v)$ EOs caused a $5.0 \log$ reduction in the growth of E. coli O157:H7 in BHI medium. When both $\mathrm{Cu}$ and LA were added at low concentrations into BHI broth, the growth of all tested strains of E. coli O157:H7 was significantly inhibited $(p<0.05)$. These results clearly indicate that both EOs and a combination of $\mathrm{Cu}$ and LA can be used to achieve a $5.0 \mathrm{log}$ reduction of pertinent pathogens. However, $\mathrm{Cu}$ and LA at low concentrations could be a practical alternative to EOs in order to achieve $5.0 \mathrm{log}$ reductions in food products for industrial applications. Further studies are needed to better understand the effectiveness of $\mathrm{Cu}$ and LA on the growth of E. coli O157:H7 in different food models.

Acknowledgments: This work was supported by the Agricultural Research Program at North Carolina Agricultural and Technical State University with funding from the USDA National Institute of Food and Agriculture, Hatch project number NC.X-234-5-09-170-1 and Food Safety Research, Teaching and Outreach Consortium for The Associates of 1890 Research Directors (ARD) Land -Grant Universities.

Conflicts of Interest: The authors declare no conflict of interest.

\section{References}

1. Centers for Disease Control and Prevention (CDC). CDC Estimates of Foodborne Illness in the United States, CDC 2011 Estimates: Factsheet Findings Updated on April 2013. Available online: http://www.cdc.gov/foodborneburden/pdfs/factsheet_a_findings_updated4-13.pdf (accessed on 22 February 2016).

2. Abdulmumeen, H.A.; Risikat, A.N.; Sururah, A.R. Food: Its preservatives, additives and applications. Int. J. Chem. Biol. Sci. 2012, 1, 36-47.

3. Gyawali, R.; Ibrahim, S.A. Natural products as antimicrobial agents. Food Control 2014, 46, 412-429. [CrossRef]

4. Tajkarimi, M.M.; Ibrahim, S.A.; Cliver, D.O. Antimicrobial herb and spice compounds in food. Food control 2010, 21, 1199-1218. [CrossRef] 
5. Gyawali, R.; Ibrahim, S.A.; Abu Hasfa, S.H.; Smqadri, S.Q.; Haik, Y. Antimicrobial activity of copper alone and in combination with lactic acid against Escherichia coli O157: H7 in laboratory medium and on the surface of lettuce and tomatoes. J. Pathog. 2011, 2011. [CrossRef]

6. Ibrahim, S.A.; Yang, H.; Seo, C.W. Antimicrobial activity of lactic acid and copper on growth of salmonella and Escherichia coli O157: H7 in laboratory medium and carrot juice. Food Chem. 2008, 109, 137-143. [CrossRef] [PubMed]

7. Shah, B.; Davidson, P.M.; Zhong, Q. Antimicrobial activity of nanodispersed thymol in tryptic soy broth. J. Food Prot. 2013, 76, 440-447. [CrossRef] [PubMed]

8. Imelouane, B.; El Bachiri, A.; Ankit, M.; Khedid, K.; Wathelet, J.-P.; Amhamdi, H. Essential oil composition and antimicrobial activity of Artemisia herba-alba Asso grown in Morocco. Banat. J. Biotechnol. 2010, 1, 48-55.

9. Friedman, M.; Henika, P.R.; Mandrell, R.E. Bactericidal activities of plant essential oils and some of their isolated constituents against Campylobacter jejuni, Escherichia coli, Listeria monocytogenes, and Salmonella enterica. J. Food Prot. 2002, 65, 1545-1560. [PubMed]

10. Al-Holy, M.A.; Castro, L.F.; Al-Qadiri, H. Inactivation of Cronobacter spp. (Enterobacter sakazakii) in infant formula using lactic acid, copper sulfate and monolaurin. Lett. Appl. Microbial. 2010, 50, 246-251. [CrossRef] [PubMed]

11. US Food and Drug Administration. Hazard. Analysis and Critical Control Point (HACCP); Procedures for the Safe and Sanitary Processing and Importing of Juice; Final Rule (21 CFR Part 120). Federal Register US Food and Drug Administration: Washington, DC, USA, 2001; Volume 66, pp. 6138-6202.

12. Bassolé, I.H.N.; Juliani, H.R. Essential oils in combination and their antimicrobial properties. Molecules 2012, 17, 3989-4006. [CrossRef] [PubMed]

(C) 2016 by the authors; licensee MDPI, Basel, Switzerland. This article is an open access article distributed under the terms and conditions of the Creative Commons by Attribution (CC-BY) license (http://creativecommons.org/licenses/by/4.0/). 